\title{
A NEW SUBCLASS OF HARMONIC MEROMORPHIC FUNCTIONS INVOLVING QUANTUM CALCULUS
}

\author{
Huda Aldweby and Maslina Darus
}

\begin{abstract}
In this article, we introduce a new subclass of harmonic meromorphic functions which are defined by means of quantum calculus ( $q$-calculus). With that, we study various interesting properties of this class. Further, $q$-integral operator is also defined and we show that the new class aforementioned is closed under this $q$-operator.
\end{abstract}

Mathematics subject classification (2010): 30C45, 33C20, 30C85.

Keywords and phrases: Harmonic meromorphic function; Starlike function; Quantum calculus; $q$ integral operator.

\section{REFERENCES}

[1] A. Aral and V. Gupta, On q-Baskakov type operators. Demonstratio Math., 42, 1(2009), 109-122.

[2] A. ARAl And V. Gupta, Generalized q-Baskakov operators, Math. Slovaca., 61, 4(2011), 619-634.

[3] A. Aral and V. Gupta, On the Durrmeyer type modification of the q-Baskakov type operators, Nonlinear Anal-Theor, 72(2010), 1171-1180.

[4] G. A. Anastassiou And S. G. GaL, Geometric and approximation properties of some singular integrals in the unit disk. J. Ineq. Appl., Article ID 17231 (2006), 19 pages.

[5] G. A. Anastassiou And S. G. GAL, Geometric and approximation properties of generalized singular integrals in the unit disk, J. Korean Math. Soc., 43, 2(2006).

[6] A. ARAL, On the generalized Picard and Gauss Weierstrass singular integrals, J. Comput. Anal. Appl., 8, 3 (2006), 246-261.

[7] A. Aral, V. G. RaVi And P. Agarwal, Applications of q-Calculus in Operator Theory, New York, NY : Springer, 2013.

[8] H. Aldweby AND M. DaRus, A subclass of harmonic univalent functions associated with qanalogue of Dziok-Srivatava operator, ISRN Math. Anal., Article ID 382312 (2013), 6 pages.

[9] H. AldweBy AND M. DARUS, A subclass of harmonic meromorphic functions associated with basic hypergeometric function, Sci. World J., Article ID 164287 (2013), 7 pages.

[10] H. Aldweby AND M. Darus, Some Subordination Results on q-Analogue of Ruscheweyh differential operator, Abstr. Appl. Anal., Article ID 958563 (2014), 6 pages.

[11] K. Al-ShaQSi AND M. DARUS, On meromorphic harmonic functions with respect to $k$-symmetric points, J. Ineq. Appl., Article. 259205 (2008), 11 pages.

[12] H. Bostanci And M.OzTURK, New classes of Salagean type meromorphic harmonic functions, Int. J. Math. Sci., 2 (2008), 52-57.

[13] J.M. JAhANGIRI AND H. Silverman, Harmonic meromorphic univalent functions with negative coefficients, Bull. Korean Math. Soc., 36 (1999), 291-301.

[14] F. H. JACKSON, On q-definite integrals, Q. J. Pure Appl. Math., 41 (1910), 193-203.

[15] F. H. JACKSON, On q- functions and a certain difference operator, Trans. R. Soc. Edin., 46 (1908), 253-281.

[16] A. Mohammed And M. DaRUs, A generalized operator involving the q-hypergeometric function, Mat. Vesnik, 65, 4(2013), 454-465. 